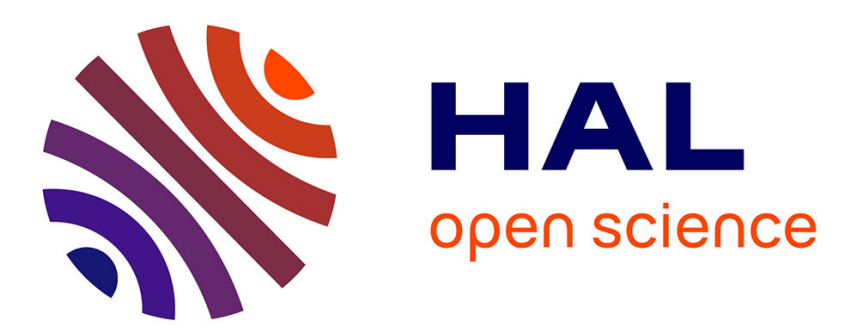

\title{
Stomatal conductance and root-to-shoot signalling in chestnut saplings exposed to Phytophthora cinnamomi or partial soil drying
}

Marion Maurel, Cécile C. Robin, Thierry T. Simonneau, Denis Loustau, Erwin Dreyer, Marie Laure Desprez-Loustau

\section{To cite this version:}

Marion Maurel, Cécile C. Robin, Thierry T. Simonneau, Denis Loustau, Erwin Dreyer, et al.. Stomatal conductance and root-to-shoot signalling in chestnut saplings exposed to Phytophthora cinnamomi or partial soil drying. Functional Plant Biology, 2004, 31 (1), pp.41-51. hal-02678692

\section{HAL Id: hal-02678692 \\ https: / hal.inrae.fr/hal-02678692}

Submitted on 31 May 2020

HAL is a multi-disciplinary open access archive for the deposit and dissemination of scientific research documents, whether they are published or not. The documents may come from teaching and research institutions in France or abroad, or from public or private research centers.
L'archive ouverte pluridisciplinaire HAL, est destinée au dépôt et à la diffusion de documents scientifiques de niveau recherche, publiés ou non, émanant des établissements d'enseignement et de recherche français ou étrangers, des laboratoires publics ou privés. 


\title{
Stomatal conductance and root-to-shoot signalling in chestnut saplings exposed to Phytophthora cinnamomi or partial soil drying
}

\author{
Marion Maurel ${ }^{\mathrm{A}}$, Cécile Robin ${ }^{\mathrm{A}}$, Thierry Simonneau ${ }^{\mathrm{B}}$, Denis Loustau ${ }^{\mathrm{C}}$, Erwin Dreyer ${ }^{\mathrm{D}}$ and \\ Marie-Laure Desprez-Loustau ${ }^{\mathrm{A}, \mathrm{E}}$ \\ AUMR INRA-Université Bordeaux 1 BIOGECO, Équipe de Pathologie Forestière, Centre INRA de Bordeaux, \\ Domaine de la Grande-Ferrade, BP81, 33883 Villenave d'Ornon Cedex, France. \\ ${ }^{\mathrm{B}}$ INRA MONTPELLIER, Laboratoire d'Écophysiologie des Plantes Sous Stress Environnementaux, \\ 2, place Viala, 34060 Montpellier Cedex 01, France. \\ ${ }^{\mathrm{C}}$ INRA Bordeaux, Unité de Recherches Forestières, Équipe d'Écophysiologie, Pierroton, 33610 Cestas, France. \\ DUMR INRA-Université Nancy I: Ecologie et Écophysiologie Forestières, Champenoux, 54280 Seichamps, France. \\ ${ }^{\mathrm{E}}$ Corresponding author; email: loustau@bordeaux.inra.fr
}

\begin{abstract}
The effects of root infection by Phytophthora cinnamomi on stomatal conductance in Castanea sativa L. saplings were investigated to determine the potential role of root-derived chemical signals. A split-root experiment was carried out, in which inoculation of the pathogen or drought was applied to the root systems in either one or both compartments. At the end of the experiment plant sap extracts were collected and their effects on stomatal conductance were determined by leaf bioassay. Inoculation or drought imposed in both compartments resulted in decreases in stomatal conductance $\left(g_{\mathrm{s}}\right)$, transpiration rate, soil-to-leaf specific hydraulic conductance, leaf water potential, xylem [ABA] and root biomass, but not in the ratio of root-to-leaf mass in inoculated plants. Conversely, only $g_{\mathrm{s}}$ and xylem $[\mathrm{ABA}]$ were affected in plants inoculated or droughted in one compartment, and no changes were detectable in leaf water potential and soil-to-leaf specific hydraulic conductance. The leaf bioassay showed that $g_{\mathrm{s}}$ in chestnut was sensitive to ABA but not to Phytophthora elicitins. Stomatal conductance was reduced by some sap extracts, both from control and inoculated plants. Our results suggest the involvement of different signals, chemical and hydraulic, in regulating stomatal conductance of chestnut at different stages of stress.
\end{abstract}

Keywords: ABA, Castanea sativa L., split-root, water stress.

\section{Introduction}

Phytophthora cinnamomi Rands is one of the most serious pathogens of woody species, affecting over 900 host plants, and is widespread in temperate, sub-tropical and tropical areas (Zentmyer 1980). P. cinnamomi causes destructive diseases in crops and major disturbances in natural plant communities where it has been introduced. For example, the devastation of some eucalypt forests and heathlands in Australia (Shearer and Tippett 1989) and the decline of chestnut in south-eastern United States and southern Europe (Grente 1961; Zentmyer 1980) have been attributed to the pathogen. P. cinnamomi develops in the cortical tissues of host plants. The primary symptoms are lesions that occur first in the small absorbing roots (Dawson and Weste 1984; Cahill et al. 1989). Secondary symptoms, such as microphylly, foliage yellowing, wilting, shoot death (Zentmyer 1980;
Shearer and Tippett 1989) and changes in variables associated with plant water relations (Dawson and Weste 1982) resemble those induced by drought and eventually result in decline and tree death in susceptible species.

A decrease in stomatal conductance of plants infected by P. cinnamomi has been reported (Dawson and Weste 1982; Crombie and Tippett 1990). However, it is unclear if this response results from disease-induced water stress caused by impaired water uptake, or from parasite or parasiteinduced chemical signals. In Persea americana and Eucalyptus sieberi, reduced stomatal conductance was associated with a decrease in leaf water potential and in soil-toleaf hydraulic conductance or root conductivity (Sterne et al. 1978; Dawson and Weste 1984). However, in other studies, the decrease in stomatal conductance was the first detectable response to infection as demonstrated in

Abbreviations used: C, control treatment; D, droughted treatment; E, excised treatment; $E$, whole-plant transpiration flux density; $g_{\mathrm{s}}$, stomatal conductance; I, inoculated treatment; KSL, soil-to-leaf specific hydraulic conductance; LA, final leaf area; NR, necrotic root ratio; PPFD, photosynthetic photon flux density; RH, relative humidity; SWC, soil volumetric water content; VPD, vapour pressure deficit; $\Psi_{\text {Lpredawn }}$ and $\Psi_{\text {Lmidday }}$ water potential of leaf measured before dawn and in the middle of the day, respectively. 
E. marginata (Crombie and Tippett 1990), Isopogon ceratophyllus (Dawson and Weste 1982), Quercus spp. (Robin et al. 1998, 2001; Maurel et al. 2001a) and Castanea sativa (Maurel et al. 2001a, b). In the latter study, stomatal conductance decreased linearly with the percentage of necrotic roots but leaf water potential and soil-to-leaf specific hydraulic conductance were not affected until the percentage of necrotic roots reached $50-60 \%$.

The regulation of stomatal conductance by hydraulic and/or chemical signals in plants exposed to drought stress has been studied widely (Davies and Zhang 1991; Tardieu and Davies 1993; Croker et al. 1998; Bond and Kavanagh 1999; Comstock 2002; Lovisolo et al. 2002). In some species, decreased stomatal conductance was closely related to a decrease in leaf water potential, suggesting hydraulic control of stomata. However, in several other species, the decrease in stomatal conductance associated with water deficit did not appear to be mediated by decreasing leaf water potential. In addition, stomatal closure induced by stress in the root environment in the absence of water deficit has also been reported (Jackson and Hall 1987). These observations support the hypothesis that a root-to-shoot chemical signal triggers stomatal closure and ABA has been extensively studied as the most likely messenger (Wilkinson and Davies 2002). In several studies, the decrease in stomatal conductance was associated with an increase in ABA in the xylem sap (Blake and Ferrell 1977; Tardieu et al. 1992, 1996; Khalil and Grace 1993; Loewenstein and Pallardy 1998; Chen et al. 2002). However, no such correlation between stomatal conductance and xylem sap ABA was found in Quercus species (Triboulot et al. 1996; Augé et al. 2000).

Comparatively few studies have addressed the regulation of stomatal conductance, especially the role of chemical signals, in plants exposed to biotic stress induced by parasites. The possible role of ABA has only been considered for systemic phloem phytoplasmas and xylem bacteria, with contrasting results (Martinez et al. 2000; Tan and Whitlow 2001; Gomes et al. 2003). However, increased concentrations of endogenous ABA have been reported to occur in various plants in response to fungal infection and have been attributed to different processes involving both fungal ABA biosynthesis and a fungal effect on plant ABA biosynthesis (Kettner and Dörffling 1995). In the case of Phytophthora infections, localised changes in ABA concentrations in infected plants have been observed and the possible role of abscisic acid in regulating resistance responses has been suggested (Mohr and Cahill 2001). The role of ABA as a root-to-shoot signal in $P$. cinnamomi infection has not been investigated but indirect evidence for its involvement was provided by Cahill et al. (1986). They demonstrated a drastic reduction in cytokinins present in the xylem sap shortly after infection by $P$. cinnamomi and suggested that the change in the balance between cytokinins and ABA might be a major cause of the modification to water transport in infected Eucalyptus marginata trees. Other fungal or infection-related molecules could be involved in the stomatal response, such as microbial toxins (e.g. the well known fusicoccin, Marré 1979; Di Giorgio et al. 1996), fungal elicitors (de Wit 1995; Netting 2000), cell wall degradation products (Lee et al. 1999) and phytoalexins produced by plants in response to pathogen attack (Willmer and Plumbe 1986).

Phytophthora elicitins are possible signals involved in the stomatal response to infection. Elicitins are a family of small proteins with a high degree of homology secreted by Phytophthora species. They elicit defence reactions in tobacco (Ricci et al. 1993) and a few other species (Kamoun et al. 1993; Bonnet et al. 1996) and were shown to be sterol carriers (Mikes et al. 1998). Their translocation from roots to shoots through the vascular system was demonstrated in tobacco (Devergne et al. 1992; Zanetti et al. 1992). Among elicitins, cryptogein has been studied most extensively. The biological activity of cryptogein in tobacco cells was shown to be associated with binding at plasma membrane sites. This induces a cascade of signal transduction events, including $\mathrm{Ca}^{2+}$ influx, extracellular medium alkalization, and active oxygen species production (Bourque et al. 1998). Cryptogein reduced the fusicoccin-induced acidification of the extracellular medium in treated tobacco cell suspension cultures (Blein et al. 1991). In oak a basic elicitin related to cryptogein, quercinin, was shown to be produced by P. quercina in infected root tissue (Heiser et al. 1999; Brummer et al. 2002). This led Osswald et al. (2000) to suggest that this elicitin might be transported from roots to leaves in oak trees infected by P. quercina and be involved in the mechanism of decline.

The objective of our study was to investigate the contribution of hydraulic and chemical signals to explain the stomatal response in Castanea sativa saplings infected by P. cinnamomi, in comparison with the effects of drought. Chestnut saplings were grown in pots that allowed the root systems to be split between two compartments, a method that has previously been used successfully to investigate the occurrence of root signals (Fort et al. 1997 1998; Mulholland et al. 1999; Lovisolo et al. 2002). The possible involvement of chemical signals to regulate stomatal conductance was investigated by analysing (1) changes in stomatal conductance in relation to predawn leaf water potential and soil-to-leaf hydraulic conductance, (2) ABA concentrations in the xylem sap and (3) the effects of xylem sap, ABA and elicitin solutions on stomatal conductance in a leaf bio-assay.

\section{Materials and methods}

\section{Plant material and growth conditions}

Chestnut seeds (Castanea sativa L., provenance: Gironde, France) were surface-disinfected by immersing them in 'Desogerme' (active 
ingredient: quaternary ammonium salt, $1 \% \mathrm{v} / \mathrm{v}$, Laboratoires ACI International, Lyon, France) for $1 \mathrm{~h}$ and placed on wet filter paper to germinate in the laboratory. Taproots were cut when $20 \mathrm{~mm}$ long to allow the formation of new roots. After one month's growth in perlite in the laboratory, the seedlings were gently removed. For each seedling, two roots of equivalent length and diameter were selected and all other roots were removed. Seedlings were grown in 14-L split-root pots divided vertically in two watertight compartments, identical to those used by Fort et al. $(1997,1998)$. Each root was placed into one of the separate compartments containing a sand-peat $(2 / 1 \mathrm{v} / \mathrm{v})$ mixture. The plants were grown in a non-heated glasshouse for two growing seasons from March 1999 to the end of the experiment in July 2000. They were fertilized weekly with 'Plantprod' $\left(2 \mathrm{~g} \mathrm{~L}^{-1}, \mathrm{~N} / \mathrm{P} / \mathrm{K} 20 / 20 / 20\right.$ and oligoelements, Plant Products Co. Ltd, Brampton, Ontario, Canada). Watering was by automatic drip irrigation twice a day, completed by manual irrigation if needed to maintain the soil volumetric water content (SWC, \%) in each compartment at around $18 \%$. SWC was measured with time domain reflectometry (200-mm long probe, Soil Moisture Equipment Corp., Santa Barbara, CA). For each compartment, SWC was calculated from the mean of three measurements.

\section{Treatments}

Plants were assigned to six treatments: control plants (CC), plants with one control compartment and the other compartment infested with P. cinnamomi (CI) or droughted (CD) or with the root system excised (CE), plants with both compartments infested with P. cinnamomi (II) or droughted (DD). Four replicate plants were used in the $\mathrm{CC}, \mathrm{CD}, \mathrm{CE}$ and DD treatments, six in the CI and II treatments.

The inoculation was performed at the end of the first growing season in order to give time for symptoms to develop during the subsequent months. Drought and excision treatments, that induce more rapid development of stress, were carried out during the second growing season. Measurements of water relations were made during the second growing season. Dates hereafter refer to the day of year since 1 January in the second growing season (2000).

\section{Inoculation}

A detailed description of the inoculation technique is given by Maurel et al. (2001a). Millet seeds (10 mL) infected with P. cinnamomi isolate 9 (Robin and Desprez-Loustau 1998) were inserted into 80 -mm-deep holes made in the growth medium in the middle of the compartments to be inoculated. The growth medium was saturated once with water to enhance the production of secondary inoculum, and then watered normally. The survival of $P$. cinnamomi in the substrate of all infested compartments (I) and the absence of P. cinnamomi in noninfested compartments (C, D and E) was checked by a baiting method (Robin et al. 1998) at the beginning of the second growing season.

\section{Watering treatments}

Water supply in dry (D) compartments was reduced by half, by removing one of two drip tubes in the compartments, over days 161-189; watering was then totally withheld over days 189-200, except on day 194 when $200 \mathrm{~mL}$ was provided in all D compartments in order to prevent wilting in the DD plants.

\section{Root excision}

The root system was excised in one of the two compartments of CE plants on day 161 .

\section{Measurements of water relations}

Predawn leaf water potential $\left(\Psi_{\text {Lpredawn }}\right)$ was measured with a pressure chamber (Druck Ltd, Leicester, England) on one mature leaf per plant, selected from mid-height. Stomatal conductance to water vapour $\left(g_{\mathrm{s}}\right)$ was measured in the morning $(0700-0900 \mathrm{~h})$ on the lower side of the upper fully expanded leaf of each plant using a steady-state porometer (Model 1600, Li-Cor Inc., Lincoln, NE) equipped with a broad-leaf aperture cap $\left(2 \mathrm{~cm}^{2}\right) . \Psi_{\text {Lpredawn }}$ and $g_{\mathrm{s}}$ were measured weekly from day 159 .

On days 174,179, 187 and 200, water uptake per compartment was estimated from measurements of SWC at $8.5 \mathrm{~h}, 2.25 \mathrm{~h}, 7.5 \mathrm{~h}$ and $3 \mathrm{~h}$ intervals, respectively. To avoid direct evaporation from the soil, pots were covered with polystyrene sheets between the two measurements.

Whole-plant transpiration flux density $(E)$ and soil-to-leaf specific hydraulic conductance (KSL) with reference to leaf area (LA) were estimated at the end of the experiment on day 200. Leaves of each plant were harvested and dried in order to estimate leaf area from the relationship:

$$
\text { LA }\left(\mathrm{m}^{2}\right)=1.45710^{-2} \mathrm{DM}\left(R^{2}=0.99\right),
$$

where DM is the dry mass (g). The relationship was established on ten samples of leaves. Leaf surface area was measured after digitising the leaves using 'DeltaT Scan' Software (A T Delta-T Device, Cambridge, UK).

$E$ was calculated from the weight loss of pots over three hours. SWC was measured in each compartment just before the first weight measurement and immediately after the second measurement to estimate water uptake. This procedure confirmed the good agreement between the water uptake estimates per plant, $y$ and $x$, obtained from the gravimetric and SWC methods, respectively $(y=0.5784 x+46.528$, $R^{2}=0.77$ ).

KSL was estimated from $E$ and predawn and midday leaf water potential ( $\left.\Psi_{\text {Lmidday }}, \mathrm{MPa}\right)$ measurements on the same day from:

$$
\mathrm{KSL}=E /\left(\Psi_{\text {Lpredawn }}-\Psi_{\text {Lmidday }}\right) \text {. }
$$

\section{Root damage assessment}

All saplings were harvested at the end of the experiment (days 201-203). Roots were washed and examined carefully. Isolations from necrotic roots were made by plating $5 \mathrm{~mm}$ root segments onto PARBHy selective medium (Robin et al. 1998). For each compartment, the healthy and necrotic parts of the root system were separated visually, dried and weighed. The necrotic root ratio was then calculated as the ratio of dry mass of necrotic roots to the total root dry mass. The necrotic root ratio for each plant (NR, \%) was calculated by averaging the necrotic root ratios in the two compartments.

\section{Collection of xylem sap}

Xylem sap was collected at the end of the experiment (days 201-203). Plants from the different treatments were defoliated in the morning. Just before collection, the shoot was severed at the root collar and the top 20-30 mm were discarded. For each plant, sap was extracted from 300 -mm-long segments cut from the upper part of the main stem. For each segment, $50 \mathrm{~mm}$ length of bark were removed at each end and the cuts were covered with Parafilm to prevent contamination of the xylem sap with ABA exuding from phloem tissues (Else et al. 1994). The stem segment was then placed in a deep pressure chamber. Pressure was increased gradually to $3 \mathrm{MPa}$ and exuded sap was collected with a pipette. Volumes of sap collected were $600-700 \mu \mathrm{L}$ from control and half-stressed plants but only $150-250 \mu \mathrm{L}$ from plants in the DD and II treatments. During collection, sap was stored in a cryotube (Cryo. S, Greiner Labortechnik, Frickenhausen, Germany) on ice. At the end of extraction (when sap stopped exuding), sap samples were frozen in liquid nitrogen and stored at $-20^{\circ} \mathrm{C}$. Xylem sap samples were used for ABA concentration determination and/or in a leaf bioassay.

\section{Measurements of abscisic acid concentrations}

Abscisic acid concentration in the xylem sap was determined by radioimmuno assay with the monoclonal antibody MAC62 (Barrieu and Simonneau 2000). Within-plant variation among samples was checked 
using two plants and was found to be small: $86 ; 123 ; 128 \mathrm{~nm} \mathrm{ABA}$ and 559; 609 nм ABA, respectively.

\section{Leaf bioassay}

The methodology for leaf bioassays was adapted from Jones and Mansfield (1970), Dreyer and Scuiller (1989) and Ridolfi et al. (1996). Leaves were obtained from healthy chestnut saplings transferred from the greenhouse to the laboratory the day before the assay. Immediately before the measurements, one of the last four fully expanded leaves was cut off under water. The leaf surface was carefully dried and the petiole was put into an Eppendorf tube containing a solution of $\mathrm{KOH}$ in water at $\mathrm{pH}$ 6, then the leaf was placed in a Compact Minicuvette System (CMS400, Walz, Effeltrich, Germany) for the measurement of stomatal conductance $\left(\mathrm{PPFD}=1.1 \mathrm{mmol} \mathrm{m}^{-2} \mathrm{~s}^{-1},\left[\mathrm{CO}_{2}\right]=350 \mu \mathrm{L} \mathrm{L}^{-1}, t=25^{\circ} \mathrm{C}\right.$, VPD $=1.24 \mathrm{kPa}$, flow rate $=2200 \mathrm{~mL} \min ^{-1}$ ). When stomatal conductance had been stable for approximately $20 \mathrm{~min}$, the Eppendorf tube containing the control solution was quickly replaced by an Eppendorf tube containing $0.5 \mathrm{~mL}$ of the solution to be tested. Preliminary tests showed that this change produced no effect on stomatal conductance. The solutions used for the tests were as follows: a solution of $\mathrm{KOH}$ in water at $\mathrm{pH} 5,10^{-4} \mathrm{M}( \pm)$ cis, trans ABA (approximately $99 \%$, Sigma Chemical Co., St Louis, MO), $50 \mu \mathrm{g} \mathrm{mL}^{-1}$ elicitin solutions (cryptogein and parasiticein provided by Frank Panabières, INRA, Antibes), and sap extracts from CC, CI and II plants. Stomatal conductance was monitored for 40 min after leaf solution substitution. Leaf area was measured at the end of the experiment.

\section{Statistical analyses}

Three plants were discarded for analyses: one CE plant that had developed new roots in the excised compartment (E) and two plants (CD and DD) that had been contaminated by P. cinnamomi. Final replicate numbers were therefore three for $\mathrm{CD}, \mathrm{CE}$ and $\mathrm{DD}$, four for $\mathrm{CC}$ and six for $\mathrm{CI}$ and II treatments.

Owing to the heterogeneity of variances between treatments, nonparametric analyses were performed. The effects of the treatments were analysed with a Kruskal-Wallis test, and then, if significant, differences between each treatment and the control were tested (NPAR1WAY Procedure, SAS Institute Inc. 1990). For paired samples, such as comparisons between the effects in compartments of the same plants within a treatment, or comparison between two treatments over several dates, the Wilcoxon signed test was used.

\section{Results}

\section{Root damage, biomass and water uptake}

Root lesions developed in all infected compartments and P. cinnamomi was re-isolated from necrotic tissue of all inoculated plants. Root damage varied greatly among infected compartments, from little damage to fine roots and localised lesions on main roots, to nearly complete destruction of fine roots and finally, necrosis of the whole root system. The necrotic root ratio (NR) varied between $8-100 \%$ in infected compartments; the range was between $5-76 \%$ at the whole-plant level, with mean values of $27 \pm 22 \%$ and $41 \pm 24 \%$ in CI and II plants, respectively. In one CI plant, the lesion reached the collar and developed on the stem. No wilting was observed in any plant.

At the plant level, healthy root biomass was significantly lower than the controls for CE and II plants only. Leaf area was also reduced in II plants. Finally, all treatments resulted in a ratio of healthy root biomass to leaf biomass of close to

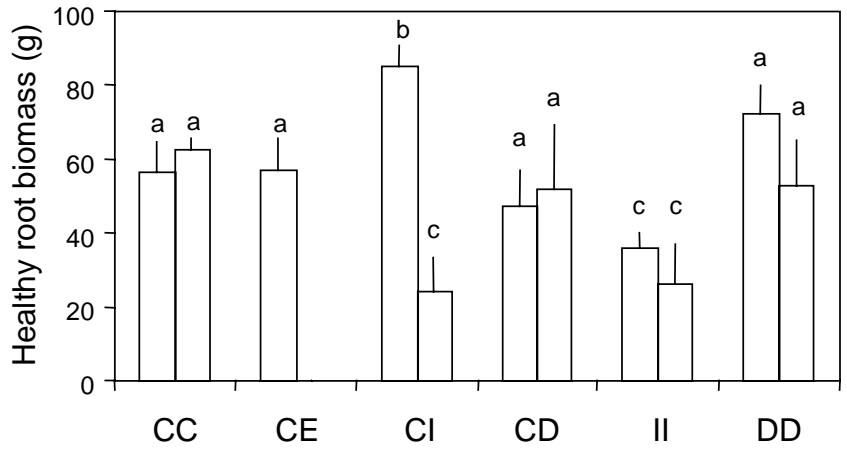

Fig. 1. Healthy root biomass per compartment in young Castanea sativa plants grown in a two-compartment split-root system. The treatments were: controls (CC), plants with one (CI) or two (II) compartment(s) infested with Phytophthora cinnamomi, plants with one (CD) or two (DD) compartment(s) submitted to drought, plants with one half of the root system excised (CE). For CE, CI, and CD treatments, the first compartment (on the left) is the control compartment (C) and the second compartment (on the right) is the excised, infested or droughted compartment (E, I, D). Error bars represent standard errors. Values with the same letter are not significantly different at $P<0.05$.

two, except for $\mathrm{CE}(<1.5)$. A large difference in root biomass between compartments was observed in CI plants; healthy root biomass was reduced significantly in inoculated compartments while it increased in the non-inoculated compartments, compared with control plants (Fig. 1). Similarly, unbalanced water uptake between inoculated (I) and control (C) compartments was demonstrated from day 174 (Fig. 2). In CD plants, a significant difference between compartments in water uptake occurred only after day 187 , i.e. $26 \mathrm{~d}$ after watering was reduced, although water uptake in the DD plants had already decreased compared to

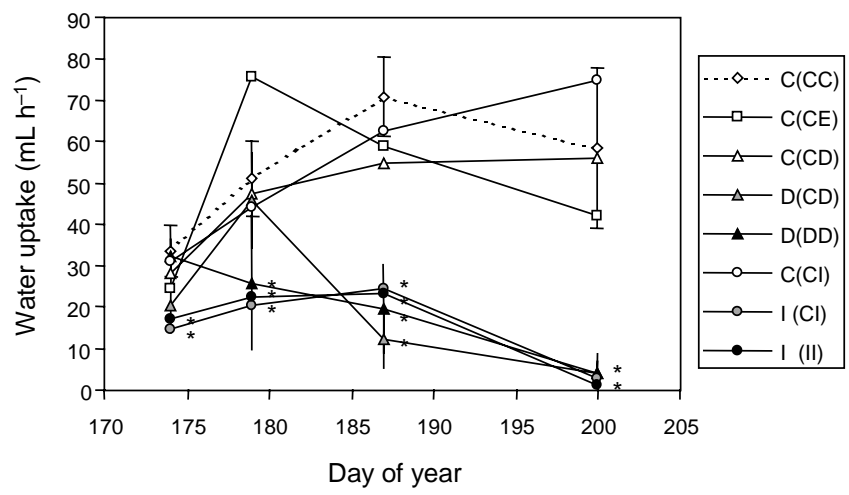

Fig. 2. Water uptake per compartment, estimated by soil volumetric water content measurements, in young Castanea sativa plants grown in a two-compartment split-root system (see Fig. 1 for treatments). Inoculation was performed the previous year in September, root excision on day 161; water deficit was initiated on day 161 and reinforced on day 189. Error bars represent standard errors (some error bars were omitted for clarity), asterisks significant differences from controls (Kruskal-Wallis test, $P<0.05$ ). 

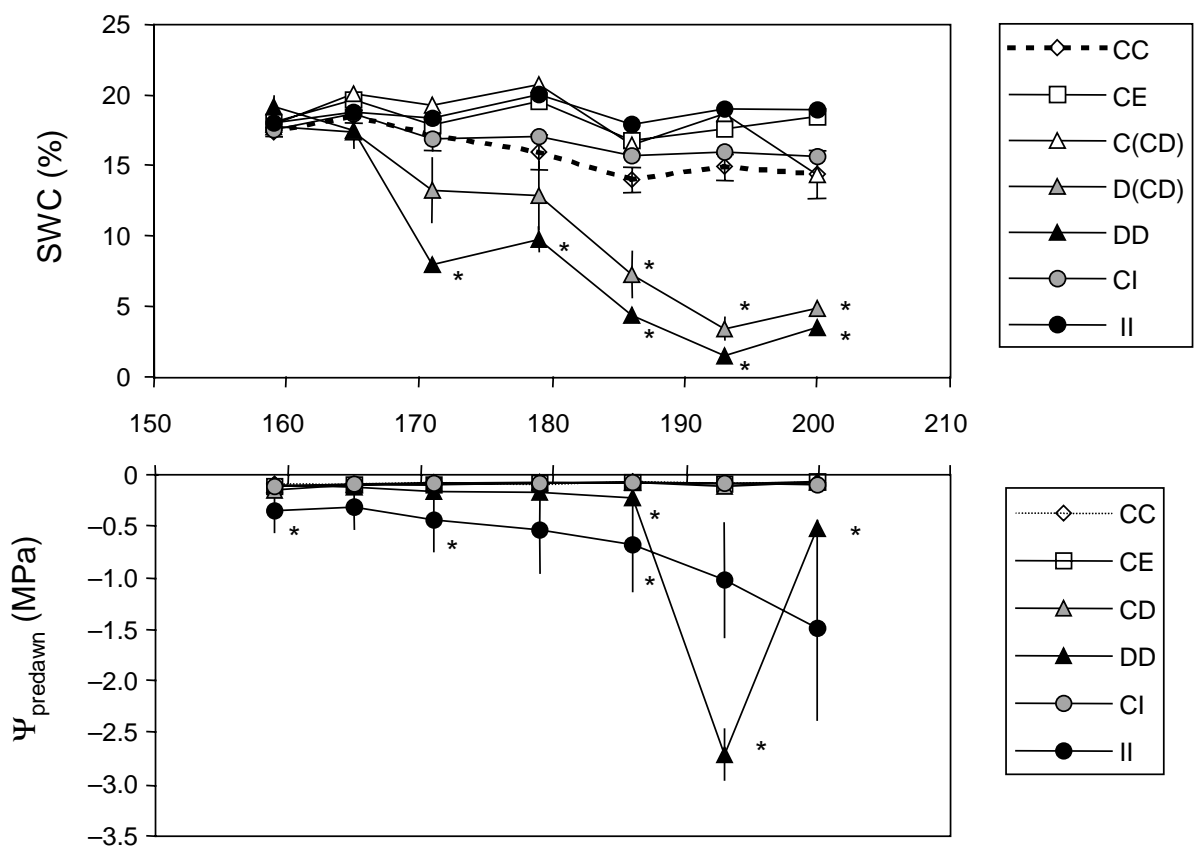

Day of year

Fig. 3. Time-course of soil volumetric water content (SWC, mean value per plant except for CD plants, given per compartment) and $\Psi_{\text {Lpredawn }}$ in young Castanea sativa plants grown in a twocompartment split-root system (see Fig. 1 for treatments). Inoculation was performed the previous year in September, root excision on day 161; water deficit was initiated on day 161 and reinforced on day 189; a limited rewatering (200 mL water per D compartment) was done on day 194. Error bars represent standard errors (some error bars were omitted for clarity), asterisks significant differences from controls (Kruskal-Wallis test, $P<0.05$ ).

that of the control plants from day 179 . Water uptake by the II plants was low throughout the measurement period.

\section{Water relations}

High predawn leaf water potentials were maintained in plants submitted to stress (infection, soil drying or root excision) in only one of the two compartments (Fig. 3). Individual values above $-0.13 \mathrm{MPa}$ were measured in plants in the CI, CD and CE treatments, like those in the control treatment (CC), throughout the experiment except for the CI plant with a shoot lesion, when $\Psi_{\text {Lpredawn }}$ was $-0.19 \mathrm{MPa}$ on the last date. $\mathrm{CI}$ and $\mathrm{CD}$ treatments were never significantly different from the $\mathrm{CC}$ treatment but the difference between the CE $(-0.10 \pm 0.01 \mathrm{MPa})$ and $\mathrm{CC}(-0.08 \pm 0.01 \mathrm{MPa})$ treatments was significant on day 171 , i.e. $10 \mathrm{~d}$ after excision of half of the root system in CE plants (Kruskal-Wallis test $=3.85, \mathrm{df}=1, P=0.0497$ ). KSL and $E$ estimated at the end of the experiment were unaffected, except $E$ for CE plants (Fig. 4) but differences in stomatal conductance were detected (Fig. 5). Values of $g_{\mathrm{s}}$ were lower in the CI plants than in the CC plants throughout the measurement period. The difference was significant between the paired $\mathrm{CI}$ and $\mathrm{CC}$ treatment means when all dates were considered, even when the CI plant with a shoot lesion was discarded (Wilcoxon signed test: $\mathrm{z}=2.197, P=0.014$ ), although there was no significant difference between $\mathrm{CC}$ and CI plants at any single date. In CE and CD plants, a transient decrease in $g_{\mathrm{s}}$ to approximately half that of control values was observed 10 and $18 \mathrm{~d}$ after the application of the treatments, respectively (Fig. 5).

Predawn leaf water potential for plants inoculated in two compartments was lower than control values throughout the

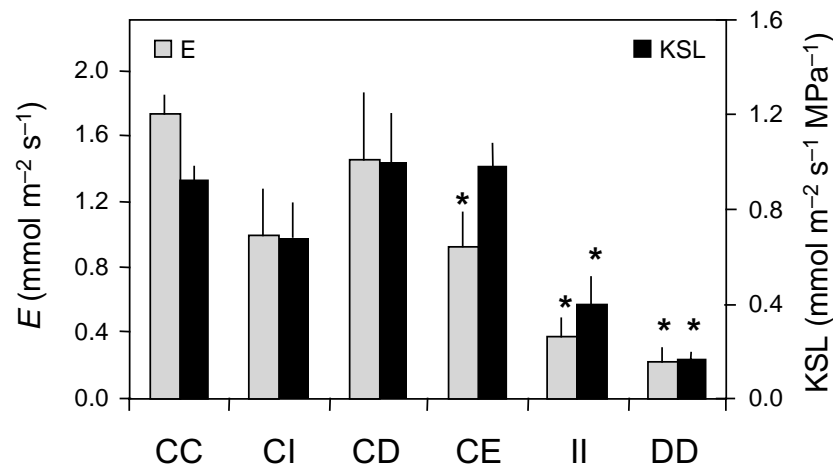

Fig. 4. Transpiration $(E)$ and soil-to-leaf specific hydraulic conductance (KSL) estimated on 18 July 2000 (day 200) in young Castanea sativa plants grown in a two-compartment split-root system (see Fig. 1 for treatments). Error bars represent standard errors, * indicates significant differences from controls. 
experiment from the first date of measurement, although very high soil water content remained (Fig. 3). A large variation between plants was observed in the decrease in $\Psi_{\text {Lpredawn }}$ so that differences were significant only on some dates. As expected, droughted plants in both compartments showed a marked decline in $\Psi_{\text {Lpredawn }}$ (Fig. 3). Only a slight decrease was observed from day 171 (i.e. $10 \mathrm{~d}$ after the watering was reduced) as long as SWC remained above 5\% $(-0.22 \mathrm{MPa}$ and $5.88 \%$ on day 186$)$. Then, a very sharp decrease in $\Psi_{\text {Lpredawn }}$ was observed when watering was completely withheld and SWC fell below $5 \%$. The decline of $\Psi_{\text {Lpredawn }}$ was associated with a significant reduction in transpiration, soil-to-leaf conductance (Fig. 4) and stomatal conductance (Fig. 5) in II and DD plants.

\section{Abscisic acid concentrations in the xylem sap}

A large range in xylem [ABA] occurred between plants, from 45-2326 nм (Fig. 6). The lowest values $(<100 \mathrm{~nm})$ were measured in two out of the three control plants and the one CD plant tested, the highest (>500 nM) for the two studied DD plants, one II and one CI plant. A general trend of decreasing $g_{\mathrm{s}}$ with increasing xylem [ABA] was observed (Fig. 6, Spearman correlation coefficient $=-0.75, P=0.0085$, $\mathrm{df}=9$ ). However, values of stomatal conductance varied greatly with $\mathrm{ABA}$ concentrations in the range 0-500 nм. Above this value, $g_{\mathrm{s}}$ was less than $80 \mathrm{mmol} \mathrm{m}^{-2} \mathrm{~s}^{-1}$.

\section{Leaf bioassay}

Stomatal conductance was steady in leaves transferred from one Eppendorf tube containing the control $\mathrm{KOH}$ solution at $\mathrm{pH} 6$ to another tube containing the same solution at either pH 5 or pH 6 (Fig. 7). The same was observed when leaves were transferred to an elicitin solution, either parasiticein or cryptogein. Conversely, when leaves were supplied with a $10^{-4}$ м ABA solution, a dramatic decline in $g_{\mathrm{s}}$ was observed within $30 \mathrm{~min}$. Very little variation in these responses was observed between the three leaves tested in each treatment.

Assays with sap extracts from the two CI plants yielded similar responses than those supplied with ABA. A sharp decrease in $g_{\mathrm{s}}$ was observed shortly after the leaf was
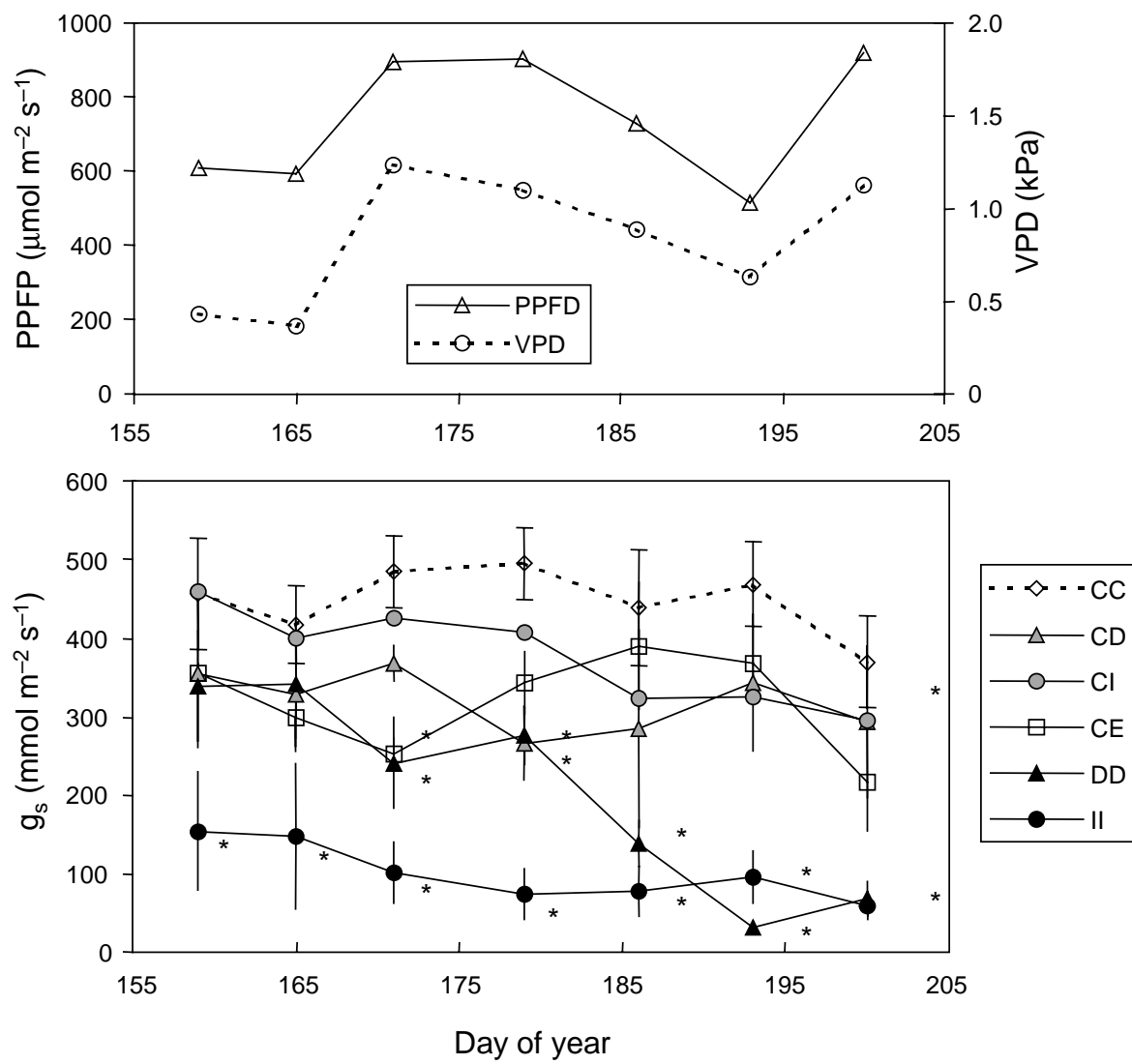

Fig. 5. Time-course of stomatal conductance $\left(g_{\mathrm{s}}\right)$ in young Castanea sativa plants grown in a twocompartment split-root system (see Fig. 1 for treatments). Vapour pressure deficit (VPD) and photosynthetic photon flux density (PPFD) are given at the time of measurements. Inoculation was performed the previous year in September, root excision on day 161; water deficit was initiated on day 161 and reinforced on day 189; a limited rewatering (200 mL water per D compartment) was done on day 194. Error bars represent standard errors (some error bars were omitted for clarity), asterisks significant differences from controls (Kruskal-Wallis test, $P<0.05$ ). 
transferred to the tube containing the sap extract (Fig. 7). Stomatal conductance also decreased with most sap extracts from CC plants. Extracts from a single II plant gave inconsistent results.

\section{Discussion}

In accordance with previous reports with other types of root stress (Fort et al. 1997; Mulholland et al. 1999), the splitroot design was adequate for maintaining shoot water status, i.e. a high predawn leaf water potential, in plants despite the fact that half of the root system was inoculated with P. cinnamomi. This allowed us to compare the effects on water relations of either localised root stress resulting from infections (in CI plants) or global infection effects including water stress (in II plants). No effects on $\Psi_{\text {Lpredawn }}$, KSL and $E$ were detected in CI plants with their inoculated compartment nearly totally destroyed (i.e. NR $=50 \%$ ) whereas $\Psi_{\text {Lpredawn }}, \mathrm{KSL}$ and $E$ decreased in II plants with necrotic ratios (NR) above the rather low thresholds of $20-30 \%$. It is worth noting that the only CI plant showing a decline in $\Psi_{\text {Lpredawn }}, \mathrm{KSL}$ and $E$ had lesions extending up to the main stem. Luque et al. (1999) similarly reported a decrease in $\Psi_{\mathrm{wp}}$ after P. cinnamomi inoculations on stems of Quercus suber.

Despite the absence of a significant decrease in transpiration rate measured at the end of the experiment, changes in stomatal conductance were demonstrated in 'half-stressed' plants during the course of the experiment. The reduction of $g_{\mathrm{s}}$ was moderate but long-lasting in half-inoculated plants. Conversely, in plants where one half of the root system was excised or droughted, the decrease in stomatal conductance was substantial but transitory in the several days following

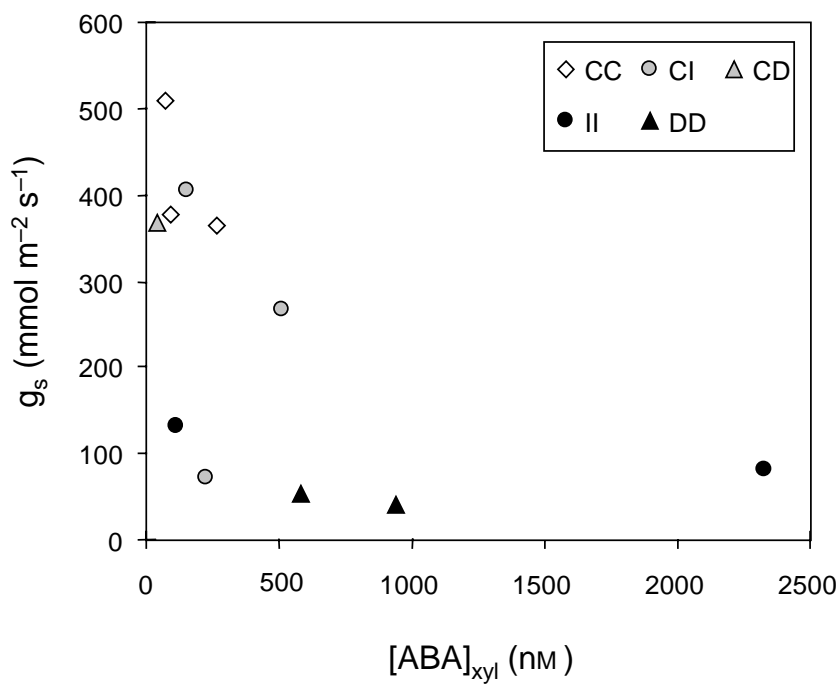

Fig. 6. Stomatal conductance $\left(g_{\mathrm{s}}\right)$ measured on 18 July 2000 (day 200 ) before sap extraction, in relation to abscisic acid concentration in the xylem sap ([ABA]xyl) in young Castanea sativa plants grown in a two compartment split-root system (see Fig. 1 for treatments). Each point represents one individual. the application of the treatment. Such a transitory response after a half-severing treatment had also been reported by Fort et al. (1997) in Quercus. In our experiment, the decrease in $g_{\mathrm{s}}$ in CE plants coincided with a slight although significant decrease in $\Psi_{\text {Lpredawn }}$, strongly supporting a hydraulic signal acting on stomata. In contrast, the stomatal decrease in response to root infection and drought in CI and CD plants was independent of leaf water potential, suggesting non-hydraulic signal(s) transported from stressed roots. This view is supported by the observation that the transitory decrease in $g_{\mathrm{s}}$ in CD plants occurred when sap flux from the compartment exposed to drought was still significant, as inferred from measurements of water uptake. The slight reduction in $g_{\mathrm{s}}$ in CI plants coincided with a low contribution to total water uptake by roots in the inoculated compartments over the whole measurement period.

The analyses of xylem sap ABA concentration and the effects on reduced stomatal conductance in the leaf bioassays provide further evidence for the possible occurrence of root-to-shoot signals associated with root stress, induced by infection or drought. Xylem sap ABA increased with root stress and chestnut stomata exhibited a strong sensitivity to ABA. Xylem sap ABA concentrations in control plants were within the range of values reported for other species, especially in the Fagaceae, Q. robur (Fort et al. 1997), Q. petraea (Triboulot et al. 1996) and Q. alba (Loewenstein and Pallardy 1998). Much higher values were observed in some of the plants with one or both compartments infected or droughted. The low value in the CD plant might have been attributable to a dilution effect since a comparatively high volume of sap was extracted from this plant $(1400 \mu \mathrm{L})$ (Borel and Simonneau 2002). These results are in accordance with earlier reports of an increased ABA concentration induced by drought (Davies and Zhang 1991; Khalil and Grace 1993) or other abiotic (Jackson and Hall 1987) or biotic stresses (Kettner and Dörffling 1995). A general trend of decreasing stomatal conductance with increasing [ABA] was observed, as often reported (Blake and Ferrell 1977; Zhang and Davies 1989; Tardieu et al. 1992; Khalil and Grace 1993; Loewenstein and Pallardy 1998; Chen et al. 2002). The leaf bioassay confirmed the responsiveness of chestnut stomata to ABA at concentrations commonly used in studies with other species (Trejo et al. 1995; Ridolfi et al. 1996; Martinez et al. 2000).

Conversely, elicitins showed no effect on stomatal conductance. Parasiticein and cryptogein, which are easily purified, were used instead of cinnamomin but similar effects would be expected since all elicitins are closely related and present very similar structures and functions (Ricci et al. 1993; Bourque et al. 1998). Decreases in stomatal conductance might have been expected since cryptogein showed antagonistic effects to those of fusicoccin in tobacco cells (Blein et al. 1991). Our results on chestnut leaves might be explained by a failure in the early 
steps required for elicitin recognition and/or signal transduction events. Osman et al. (2001) reported a link between the degree of tobacco cell responses (extracellular alkalization, calcium uptake) and elicitin-binding on receptors. These receptors were present on all the plant plasma membranes assayed so far (Ponchet et al. 1999), although studies were not made on members of Fagaceae. However, mechanisms could occur that prevent elicitins accessing plasma membrane receptors, such as the trapping of elicitin molecules in plant cell walls, as demonstrated in tomato (Ponchet et al. 1999).

Other chemicals in the xylem sap from stressed and control plants might induce stomatal closure, as suggested by the leaf bioassay. Martinez et al. (2000) similarly observed a reduction in transpiration in a detached coconut leaf bioassay with sap extracts of both healthy and diseased plants. Changes in $\mathrm{pH}$ might be involved since apoplastic $\mathrm{pH}$ of the substomatal cavity, which plays a determinant role in stomatal movement, was shown to be sensitive to various stress factors (Wilkinson and Davies 1997; Netting 2000; Felle and Hanstein 2002).
Overall, our results support the involvement of chemical signals in the stomatal response of chestnut saplings to local root stress caused by P. cinnamomi, at least at some stages of infection. However, no indication of a signal specifically induced by the parasite was obtained. The Phytophthoraspecific elicitins tested induced no detectable response in stomata. The signal associated with root infection might be $\mathrm{ABA}$, as already demonstrated with other root stress factors in several species (Jackson and Hall 1987; Davies and Zhang 1991; Khalil and Grace 1993; Kettner and Dörffling 1995) and suggested for drought in our experiment. The difficulty in experimentally maintaining different types of stress accounts for the lack of resolution in the timing of our measurements of stomatal conductance, leaf water potential and xylem sap concentrations in the different treatments. However, our results lend support to the hypothesis that several mechanisms, including both chemical and hydraulic signals, are involved and integrated to regulate stomatal conductance (Comstock 2002; Liu et al. 2003). The involvement of rootsourced signals, especially ABA, would be restricted to subcritical stress levels (Mulholland et al. 1996, 1999;
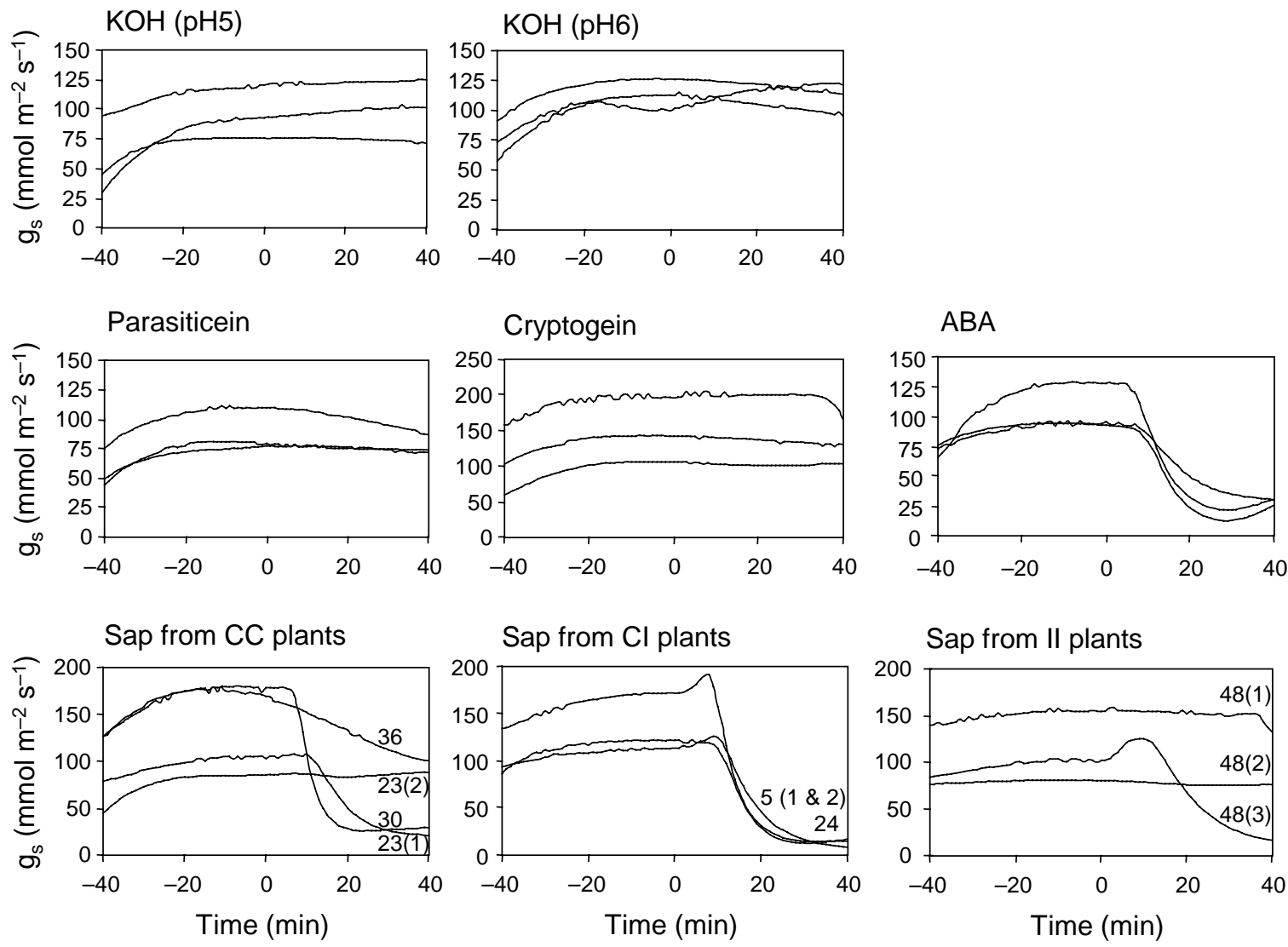

Fig. 7. Time course of $g_{\mathrm{s}}$ in chestnut detached leaves in a $\mathrm{KOH}$ solution ( $\mathrm{pH} 6$ ) from -40 min to time 0 , and then transferred to various solutions. Three different leaves were used in each treatment (four with sap extracts from CC plants). Values of $g_{\mathrm{s}}$ (in mmol m $\mathrm{s}^{-1}$ ) and [ABA] (in nM) for plants from which sap was obtained were the following: plant \#36: $g_{\mathrm{s}}=376,[\mathrm{ABA}]=96$; $\# 23: g_{\mathrm{s}}=508,[\mathrm{ABA}]=69 ; \# 30: g_{\mathrm{s}}=365,[\mathrm{ABA}]=268 ; \# 5: g_{\mathrm{s}}=374,[\mathrm{ABA}]=$ n.d., $\# 24: g_{\mathrm{s}}=454$, [ABA] = n.d.; \#48: $g_{\mathrm{s}}=133$, $[\mathrm{ABA}]=113$. 
Peterlunger et al. 2000; Liu et al. 2003). When more severe stress occurs, the relative sap flux from the stressed roots decreases, as demonstrated in CD plants in our experiment, therefore causing an increasing dilution of potential rootsourced signals in the overall transpiration flux (Gallardo et al. 1994; Fort et al. 1997). At high stress levels, hydraulic signals may become more significant, as observed in II and DD plants. In plants submitted to chronic stress, such as inoculated plants, other mechanisms might be implicated. The compensatory root growth in the non-inoculated compartments of the CI plants, as well as the maintenance of the root-to-shoot ratio in II plants, demonstrated long-term adjustments to impaired water uptake in infected plants. It has been suggested that an inherently lower stomatal conductance associated with reductions in stomatal frequency and/or guard cell size during leaf ontogeny might occur in diseased plants (Tan and Whitlow 2001). Such an hypothesis, and more generally the role, nature and temporal evolution of signals and stomatal responses elicited by $P$. cinnamomi infection, deserve further investigation.

\section{Acknowledgments}

We are grateful to Xavier Capdevielle, Gilles Capron and Olivier Fabreguette for skillful technical assistance and to Franck Panabières for kindly providing elicitins. We thank David Whitehead for the English revision of the manuscript and two anonymous reviewers for helpful comments. This work is a part of Marion Maurel's PhD thesis, with financial support from the Commission of the European Communities, Agriculture and Fisheries (FAIR) specific RTD Program CT 97-3926 'Long-term dynamics of oak ecosystems: assessment of the role of root pathogens and environmental constraints as interacting decline inducing factors' ('PATHOAK').

\section{References}

Augé RM, Green CD, Stodola AJW, Saxton AM, Olinick JB, Evans RM (2000) Correlations of stomatal conductance with hydraulic and chemical factors in several deciduous tree species in a natural habitat. New Phytologist 145, 483-500. doi:10.1046/J.1469-8137. 2000.00604.X

Barrieu P, Simonneau T (2000) The monoclonal antibody MAC252 does not react with the $(-)$ enantiomer of ABA. Journal of Experimental Botany 51, 305-307. doi:10.1093/JEXBOT/51. 343.305

Blake J, Ferrell WK (1977) The association between soil and xylem water potential, leaf resistance, and abscisic acid content in droughted seedlings of Douglas-fir (Pseudotsuga menziesii). Physiologia Plantarum 39, 106-109.

Blein JP, Milat ML, Ricci P (1991) Response of cultured tobacco cells to cryptogein, a proteinaceous elicitor from Phytophthora cryptogea. Possible plasmalemma involvement. Plant Physiology 95, 486-491.

Bond BJ, Kavanagh KL (1999) Stomatal behaviour of four woody species in relation to leaf-specific hydraulic conductance and threshold water potential. Tree Physiology 19, 503-510.
Bonnet P, Bourdon E, Ponchet M, Blein JP, Ricci P (1996) Acquired resistance triggered by elicitins in tobacco and other plants. European Journal of Plant Pathology 102, 181-192.

Borel C, Simonneau T (2002) Is the ABA concentration in the sap collected by pressurizing leaves relevant for analysing drought effects on stomata? Evidence from ABA-fed leaves of transgenic plants with modified capacities to synthesize ABA. Journal of Experimental Botany 53, 287-296. doi:10.1093/JEXBOT/53. 367.287

Bourque S, Ponchet M, Binet MN, Ricci P, Pugin A, Lebrun-Garcia A (1998) Comparison of binding properties and early biological effects of elicitins in tobacco cells. Plant Physiology 118, 1317-1326. doi:10.1104/PP.118.4.1317

Brummer M, Arend M, Fromm J, Schlenzig A, Osswald W (2002) Ultrastructural changes and immunocytochemical localization of the elicitin quercinin in Quercus robur L. roots infected with Phytophthora quercina. Physiological and Molecular Plant Pathology 61, 109-120. doi:10.1016/S0885-5765(02)90419-4

Cahill DM, Weste G, Grant BR (1986) Changes in cytokinins concentrations in xylem extrudates following infection of Eucalyptus marginata Donn ex. Smith with Phytophthora cinnamomi Rands. Plant Physiology 81, 1103-1109.

Cahill D, Legge N, Grant B, Weste G (1989) Cellular and histological changes induced by Phytophthora cinnamomi in a group of plant species ranging from fully susceptible to fully resistant. Phytopathology 79, 417-424.

Chen G, Lips SH, Sagi M (2002) Biomass production, transpiration rate end endogenous abscisic acid levels in graft of flacca and wildtype tomato (Lycopersicon esculentum). Functional Plant Biology 29, 1329-1335. doi:10.1071/PP01263

Comstock JP (2002) Hydraulic and chemical signalling in the control of stomatal conductance and transpiration. Journal of Experimental Botany 53, 195-200. doi:10.1093/JEXBOT/53.367.195

Croker JL, Witte WT, Augé RM (1998) Stomatal sensitivity of six temperate, deciduous tree species to non-hydraulic root-to-shoot signalling of partial soil drying. Journal of Experimental Botany 49, 761-774. doi:10.1093/JEXBOT/49.321.761

Crombie SD, Tippett JT (1990) A comparison of water relations, visual symptoms, and changes in stem girth for evaluating impact of Phytophthora cinnamomi dieback on Eucalyptus marginata. Canadian Journal of Forest Research 20, 233-240.

Davies WJ, Zhang J (1991) Root signals and the regulation of growth and development of plants in drying soil. Annual Review of Plant Physiology and Plant Molecular Biology 42, 55-76. doi:10.1146/ANNUREV.PP.42.060191.000415

Dawson P, Weste G (1982) Changes in water relations associated with infection by Phytophthora cinnamomi. Australian Journal of Botany 30, 393-400.

Dawson P, Weste G (1984) Impact of root infection by Phytophthora cinnamomi on the water relations of two Eucalyptus species that differ in susceptibility. Phytopathology 74, 486-490.

Devergne JC, Bonnet P, Panabières F, Blein JP, Ricci P (1992) Migration of the fungal protein cryptogein within tobacco plants. Plant Physiology 99, 843-847.

DeWit PJGM (1995) Fungal avirulence genes and plant resistance genes: unravelling the molecular basis of gene-for-gene interactions. Advances in Botanical Research 21, 147-185.

Di Giorgio D, Camoni L, Mott KA, Takemoto JY, Ballio A (1996) Syringopeptins, Pseudomonas syringae pv. syringae phytotoxins, resemble syringomycin in closing stomata. Plant Pathology 45, 564-571.

Dreyer E, Scuiller I (1989) Effects of exogenous ABA on photosynthesis and stomatal conductance of cut twigs from oak seedlings. Annales des Sciences Forestières 46 (suppl.), 406s-410s. 
Else MA, Davies WJ, Whitford PN, Hall KC, Jackson MB (1994) Concentrations of abscisic acid and other solutes in xylem sap from root systems of tomato and castor-oil plants are distorted by wounding and variable sap flow rates. Journal of Experimental Botany 45, 317-323.

Felle HF, Hanstein S (2002) The apoplastic pH of the substomatal cavity of Vicia faba leaves and its regulation responding to different stress factors. Journal of Experimental Botany 53, 73-82. doi:10.1093/JEXBOT/53.366.73

Fort C, Fauveau ML, Muller F, Label P, Granier A, Dreyer E (1997) Stomatal conductance, growth and root signalling in young oak seedlings subjected to partial soil drying. Tree Physiology 17, 281-289.

Fort C, Muller F, Label P, Granier A, Dreyer E (1998) Stomatal conductance, growth and root signalling in Betula pendula seedlings subjected to partial soil drying. Tree Physiology 18, 769-776.

Gallardo M, Turner NC, Ludwig C (1994) Water relations, gas exchange and abscisic acid content of Lupinus cosentinii leaves in response to drying different proportions of the root system. Journal of Experimental Botany 45, 909-918.

Gomes MMA, Lagôa AMMA, Machado EC, Medina CL (2003) Abscisic acid and indole-3-acetic acid contents in orange trees infected by Xylella fastidiosa and submitted to cycles of water stress. Plant Growth Regulation 39, 263-270. doi:10.1023/ A: 1022854405898

Grente J (1961) La maladie de l'encre du châtaignier. I Etiologie et biologie. Annales des Epiphyties 12, 5-24.

Heiser I, Fromm J, Giefing M, Koehl J, Jung T, Osswald W (1999) Investigations on the action of Phytophthora quercina, P. citricola and P. gonapodyides toxins on tobacco plants. Plant Physiology and Biochemistry 37, 73-81. doi:10.1016/S0981-9428(99) 80069-2

Jackson MB, Hall KC (1987) Early stomatal closure in waterlogged pea plants is mediated by abscisic acid in the absence of foliar water deficits. Plant, Cell and Environment 10, 121-130.

Jones RJ, Mansfield TA (1970) Suppression of stomatal opening in leaves treated with abscisic acid. Journal of Experimental Botany 21, 714-719.

Kamoun S, Young M, Glascock CB, Tyler BM (1993) Extracellular protein elicitors from Phytophthora: host specificity and induction of resistance to bacterial and fungal phytopathogens. Molecular Plant-Microbe Interactions 6, 15-25.

Kettner J, Dörffling K (1995) Biosynthesis and metabolism of abscisic acid in tomato leaves infected with Botrytis cinerea. Planta 196, 627-634.

Khalil AAM, Grace J (1993) Does xylem sap ABA control the stomatal behaviour of water-stressed sycamore (Acer pseudoplatanus L.) seedlings? Journal of Experimental Botany 44, 1127-1134.

Lee S, Choi H, Suh S, Doo IS, Oh KY, Choi EJ, Schroeder Taylor AT, Low PS, Lee Y (1999) Oligalacturonic acid and chitosan reduce stomatal aperture by inducing the evolution of reactive oxygen species from guard cells of tomato and Commelina communis. Plant Physiology 121, 147-152. doi:10.1104/PP.121.1.147

Liu F, Jensen CR, Andersen MN (2003) Hydraulic and chemical signals in the control of leaf expansion and stomatal conductance in soybean exposed to drought stress. Functional Plant Biology 30, 65-73. doi:10.1071/FP02185

Loewenstein NJ, Pallardy SG (1998) Drought tolerance, xylem sap abscisic acid and stomatal conductance during soil drying: a comparison of canopy trees of three temperate deciduous angiosperms. Tree Physiology 18, 431-439.
Lovisolo C, Hartung W, Schubert A (2002) Whole-plant hydraulic conductance and root-to-shoot flow of abscisic acid are independently affected by water stress in grapevines. Functional Plant Biology 29, 1349-1356. doi:10.1071/FP02079

Luque J, Cohen M, Save R, Biel C, Alvarez IF (1999) Effects of three fungal pathogens on water relations, chlorophyll fluorescence and growth of Quercus suber L. Annales des Sciences Forestières 56, 19-26.

Marré E (1979) Fusicoccin: a tool in plant physiology. Annual Review of Plant Physiology 30, 273-288. doi:10.1146/ANNUREV.PP. 30.060179 .001421

Martinez S, Cordova I, Maust BE, Oropeza C, Santamaria JM (2000) Is abscisic acid responsible for abnormal stomatal closure in coconut palms showing lethal yellowing? Journal of Plant Physiology 156, 319-322.

Maurel M, Robin C, Capron G, Desprez-Loustau ML (2001a) Effects of root damage associated with Phytophthora cinnamomi on water relations, biomass accumulation, mineral nutrition and vulnerability to water deficit of five oak and chestnut species. Forest Pathology 31, 353-369. doi:10.1046/J.1439-0329.2001. 00258.X

Maurel M, Robin C, Capdevielle X, Loustau D, Desprez-Loustau ML (2001b) Effects of variable root damage caused by Phytophthora cinnamomi on water relations of chestnut saplings. Annals of Science 58, 639-651. doi:10.1051/FOREST:2001151

Mikes V, Milat ML, Ponchet M, Panabieres F, Ricci P, Blein JP (1998) Elicitins, proteinaceous elicitors of plant defense, are a new class of sterol carrier proteins. Biochemical and Biophysical Research Communications 245, 133-139. doi:10.1006/BBRC.1998.8341.

Mohr PG, Cahill DM (2001) Relative roles of glyceollin, lignin and the hypersensitive response and the influence of ABA in compatible and incompatible interactions of soybeans with Phytophthora sojae. Physiological and Molecular Plant Pathology 58, 31-41. doi:10.1006/PMPP.2000.0306

Mulholland BJ, Black CR, Taylor IB, Roberts JA, Lenton JR (1996) Effect of soil compaction on barley (Hordeum vulgare L.) growth. I Possible role of ABA as a root-sourced chemical signal. Journal of Experimental Botany 47, 539-549.

Mulholland BJ, Hussain A, Black CR, Taylor IB, Roberts JA (1999) Does root-sourced ABA have a role in mediating growth and stomatal responses to soil compaction in tomato (Lycopersicon esculentum)? Physiologia Plantarum 107, 267-276. doi:10.1034/ J.1399-3054.1999.100303.X

Netting AG (2000) pH, abscisic acid and the integration of metabolism in plants under stressed and non-stressed conditions: cellular responses to stress and their implication for plant water relations. Journal of Experimental Botany 51, 147-158. doi:10.1093/ JEXBOT/51.343.147

Osman H, Vauthrin S, Mikes V, Milat ML, Panabières F, Marais A, Brunie S, Maume B, Ponchet M, Blein JP (2001) Mediation of elicitin activity on tobacco is assumed by elicitin-sterol complexes. Molecular Biology of the Cell 12, 2825-2834.

Osswald W, Brummer M, Schlenzig J, Koehl J, Jung T, Heiser I, Matyssek R (2000) Investigations on photosynthesis of oak seedlings infected with Phytophthora quercina and characterization of the P. quercina toxin quercinin. In 'Proceedings 1 st international meeting on Phytophthoras in forests and wildland ecosystems'. Grants Pass, Oregon, USA. (Eds EM Hansen and W Sutton) pp. 67-70. (Oregon State University: Corvallis, OR)

Peterlunger E, Bucella A, Iacono F (2000) Physiological changes in grapevine during adjustment to water stress: ABA, leaf gas exchanges and root hydraulic conductivity. Acta Horticulturae 526, 201-206. 
Ponchet M, Panabières F, Milat ML, Mikes V, Montillet JL, Suty L, Triantaphylides C, Tirilly Y, Bein JP (1999) Are elicitins cryptograms in plant-oomycete interactions? Cellular and Molecular Life Sciences 56, 1020-1047. doi:10.1007/ S000180050491

Ricci P, Panabières F, Bonnet P, Maïa N, Ponchet M, Devergne JC, Marais A, Cardin L, Milat ML (1993) Proteinaceous elicitors of plant defense responses. In 'Mechanisms of plant defense responses'. (Eds B. Fritig and M. Legrand) pp. 121-135. (Kluwer Academic Publishers: Dordrecht)

Ridolfi M, Fauveau ML, Label P, Garrec JP, Dreyer E (1996) Responses to water stress in an ABA unresponsive hybrid poplar (Populus koreana $\times$ trichocarpa $\mathrm{cv}$. Peace). I Stomatal function. New Phytologist 134, 445-454.

Robin C, Desprez-Loustau ML (1998) Testing variability in pathogenicity of Phytophthora cinnamomi. European Journal of Plant Pathology 104, 465-475, doi:10.1023/A:1008649806620

Robin C, Desprez-Loustau ML, Capron G, Delatour C (1998) First record of Phytophthora cinnamomi on cork and holm oaks in France and evidence of pathogenicity. Annales des Sciences Forestières 55, 869-883.

Robin C, Capron G, Desprez-Loustau ML (2001) Root infection by Phytophthora cinnamomi in seedlings of three oak species. Plant Pathology 50, 708-716. doi:10.1046/J.1365-3059.2001.00643.X

SAS Institute Inc. (1990). 'SAS 6.' (SAS Institute Inc.: Cary, NC)

Shearer BL, Tippett JT (1989) 'Jarrah dieback: the dynamics and management of Phytophthora cinnamomi in the Jarrah (Eucalyptus marginata) forest of south-western Australia.' Research Bulletin No. 3, Department of Conservation and Land Management, Western Australia.

Sterne RE, Kaufmann MR, Zentmyer GA (1978) Effect of Phytophthora root rot on water relations of avocado: interpretation with a water transport model. Phytopathology 68, 595-602.

Tan PY, Whitlow T (2001) Physiological responses of Catharanthus roseus (periwinkle) to ash yellows phytoplasmal infection. New Phytologist 150, 757-769. doi:10.1046/J.1469-8137.2001. 00121.X

Tardieu F, Davies WJ (1993) Integration of hydraulic and chemical signalling in the control of stomatal conductance and water status of droughted plants. Plant, Cell and Environment 16, 341-349.
Tardieu F, Zhang J, Katerji N, Bethenod O, Palmer S, Davies WJ (1992) Xylem ABA controls the stomatal conductance of fieldgrown maize subjected to soil compaction or soil drying. Plant, Cell and Environment 15, 193-197.

Tardieu F, Lafarge T, Simonneau T (1996) Stomatal control by fed or endogenous xylem ABA in sunflower: interpretation of correlations between leaf water potential and stomatal conductance in anisohydric species. Plant, Cell and Environment 19, 75-84.

Trejo CL, Clephan AL, Davies WJ (1995) How do stomata read abscisic acid signals? Plant Physiology 109, 803-811.

Triboulot MB, Fauveau ML, Bréda N, Label P, Dreyer E (1996) Stomatal conductance and xylem sap abscisic acid (ABA) in adult oak trees during gradually imposed drought. Annales des Sciences Forestières 53, 207-220.

Wilkinson S, Davies WJ (1997) Xylem sap pH increase: a drought signal received at the apoplastic face of the guard cell that involves the suppression of saturable abscisic acid uptake by the epidermal symplast. Plant Physiology 113, 559-573.

Wilkinson S, Davies WJ (2002) ABA-based chemical signalling: the co-ordination of responses to stress in plants. Plant, Cell and Environment 25, 195-210. doi:10.1046/J.0016-8025.2001. 00824.X

Willmer CM, Plumbe AM (1986) Phytoalexins, water stress and stomata. In 'Water, fungi and plants. British Mycological Society Symposium 11'. (Eds PG Ayres and L Boddy), pp. 207-222. (Cambridge University Press: Cambridge, UK)

Zanetti A, Beauvais F, Huet JC, Pernollet JC (1992) Movement of elicitins, necrosis-inducing proteins secreted by Phytophthora spp., in tobacco. Planta 187, 163-170.

Zentmyer GA (1980) 'Phytophthora cinnamomi and the diseases it causes.' (The American Phytopathological Society: St Paul, MN)

Zhang J, Davies WJ (1989) Sequential response of whole-plant water relations to prolonged soil drying and the involvement of xylem sap ABA in the regulation of stomatal behaviour of sunflower plants. New Phytologist 113, 167-174.

Manuscript received 21 July 2003, accepted 29 October 2003 